\title{
Rules of habitat use by elephants Loxodonta africana in southern Africa: insights for regional management
}

\author{
Grant M. Harris, Gareth J. Russell, Rudi I. van Aarde and Stuart L. Pimm
}

\begin{abstract}
Managers in southern Africa are concerned that continually increasing elephant populations will degrade ecosystems. Culling, translocation and birth control are flawed solutions. An alternative is providing elephants more space but this hinges on identifying landscape preferences. We examined two diverse ecosystems and uncovered similarities in elephant habitat use, expressing these as 'rules'. We considered arid Etosha National Park, (Namibia) and the tropical woodlands of Tembe Elephant Park (South Africa) and Maputo Elephant Reserve (Mozambique). Landscape data consisted of vegetation types, distances from water and settlements. To surmount issues of scale and availability we incorporated elephant movements as a function that declined as distance from an elephant's location increased. This presumes that elephants optimize tradeoffs between benefiting from high-quality resources and costs to find them. Under a likelihood-based approach we determined the important variables and shapes of their relationships to evaluate and compare models separated by gender, season and location. After consid-
\end{abstract}

ering elephants' preferences for areas nearby, habitat use usually increased with proximity to water in all locations. Elephants sought places with high proportions of vegetation, especially when neighbouring areas had low vegetative cover. Lastly, elephants avoided human settlements (when present), and cows more so than bulls. In caricature, elephants preferred to move little, drink easily, eat well, and avoid people. If one makes more areas available, elephants will probably favour areas near water with high vegetative cover (of many different types) and away from people. Managers can oblige elephants' preferences by supplying them. If so, they should anticipate higher impacts to neighbouring vegetation.

Keywords Etosha National Park, habitat use, Loxodonta africana, Maputo Elephant Reserve, optimal foraging, southern Africa, Tembe Elephant Park.

This paper contains supplementary material that can be found online at http://journals.cambridge.org

\section{Introduction}

The savannah elephant Loxodonta africana poses a dilemma for conservation managers. The IUCN categorizes the species as Vulnerable because populations in

Grant M. Harris* (Corresponding author) Nicholas School of the Environment and Earth Sciences, Duke University, PO Box 90328, LSRC A322, LaSalle St Extension, Durham, NC 27708, USA. E-mail grant_harris@fws.gov

Gareth J. Russell Department of Mathematical Sciences, New Jersey Institute of Technology, Newark, NJ 0702, USA, and Department of Biological Sciences, Rutgers University, Newark, NJ 0702, USA.

Rudi I. van Aarde and Stuart L. Pimm† Conservation Ecology Research Unit, Department of Zoology and Entomology, University of Pretoria, Pretoria 0002 , South Africa.

*Present address: US Fish and Wildlife Service, P.O. Box 1306, Albuquerque, NM 87103, USA

${ }^{\dagger}$ Also at: Nicholas School of the Environment and Earth Sciences, Duke University, PO Box 90328, LSRC A322, LaSalle St Extension, Durham, NC 27708, USA.

Received 12 March 2007. Revision requested 2 July 2007. Accepted 12 October 2007.
Central, East and West Africa are in decline (IUCN, 2007). Yet in southern Africa elephant populations grow rapidly in some protected areas (van Aarde \& Jackson, 2007). Managers are concerned that high elephant densities will harm biodiversity by degrading ecosystems (Owen-Smith, 1996; Whyte et al., 2003; Guldemond \& van Aarde, 2007). Culling, translocation and birth control are flawed solutions (van Aarde et al., 1999; Pimm \& van Aarde, 2001). Besides, there is an obvious paradox in controlling a 'natural population' by unnatural means.

In southern Africa many elephants live behind fences and managers provide artificial waterholes. Both restrict the ability of natural processes, such as dispersal, to limit populations. They also restrict seasonal movements that might ameliorate local impacts (van Aarde et al., 2006). A simple solution is to provide elephants more space. Elephants could then roam along seasonal and ecological gradients across wide areas.

This solution depends on identifying the characteristics of places that elephants inhabit. Our goal is to quantify these habitat characteristics and express any similarities in elephant habitat choices as 'rules'. We 
searched for such similarities across distinct ecosystems, using distances that elephants move plus widely available landscape-level data. Once ascertained, these rules will increase the potential to identify and assess elephant habitat in and between established populations.

We evaluated preferences of savannah elephants using global positioning system (GPS) fixes describing their movements in three disparate areas in Southern Africa: Etosha National Park in the arid savannahs of Namibia, and Tembe Elephant Park (South Africa) and Maputo Elephant Reserve, including the Futi River Corridor (Mozambique), in the eastern mesic savannahs. (Henceforth, we call these areas Etosha, Tembe and Maputo for simplicity). By design, these locations are at opposing ends of the ecological gradient spanning the historical distribution of elephant habitats in southern Africa (Douglas-Hamilton, 1987).

We combined geographic information system (GIS) data with a priori knowledge of elephant natural history to generate three variables representing those most likely to be biologically meaningful: proportions of different vegetation types, access to water, and distances from human settlements. The variables describing the proportion of vegetation cover are sometimes similar between sites. Others, such as water accessibility and distances to human settlements, are not.

\section{Methods}

\section{Scale dependence in habitat modelling}

We addressed four broad issues that spatial and temporal scales have on analyses of habitat use. The first, defining the area of availability, is obvious. Elephants 'select' Etosha, for example, where they are protected in comparison to Namibia as a whole but avoid the large saltpan within the Park. The three remaining issues are less apparent. For the second, consider that we like beer. A naive analysis of our movements over a month would reveal, counter-intuitively, that we avoid most pubs. On closer inspection, we tend to avoid only pubs further than $5 \mathrm{~km}$ from our homes. Pubs are abundant, all serve beer, and there is no reason to travel far. This example of optimal foraging is also an example of biological scale dependence: biologically, it is not sensible to expend excess energy and add risk to obtain the same objective. The strength of this dependence relies in part on an individual's mobility. If one had to walk, the pubs visited would be closer.

This biological scale dependence affects the appearance of preference. One of us favours ales, of which there are two types, NC and BA, yet local pubs never carry them together. Which does he prefer? His visitation rates reveals about equal numbers of visits to both types of pubs, suggesting no preference. Yet this would be false: he favours NC. Near his home, all pubs serve BA, which he buys. Yet often he bypasses these pubs and travels further to obtain $\mathrm{NC}$, at greater expense in time and cost. His visits to get NC, therefore, are actually much more frequent than a null model of no preference would predict, assuming it incorporates travel costs. This exemplifies issue three: models including costs improve the ability to reveal preferences.

Lastly, consider an analysis of our pub-going activities over a year. The dataset would include many pubs in surrounding towns, distant cities and other countries. This is an example of sampling scale dependence: the temporal span of observations determines the observed spatial scale of movements.

We solved these problems by including the distance between location fixes as an explicit variable. An exponential function with a single, unknown parameter that must be estimated models this effect. The value of this parameter is determined by the mobility of the elephant and the interval between GPS fixes, both of which vary between individual elephants. The biological and sampling scale dependencies are thus impossible to separate but our goal is not to interpret the distance parameters. Their purpose is to ensure that our estimates of preferences for other variables are accurate.

Note that these three forms of scale dependence are distinct from other, well-known scaling factors affecting analyses of habitat preference. Examples include the resolution of landscape data, the extent to which a landscape is classified into 'types', and observer-defined areas of analysis (White \& Garrott, 1990; Millspaugh \& Marzluff, 2001).

\section{Sites}

Tembe and Maputo are in Maputaland, the subtropical eastern savannahs of southern Africa (Fig. 1). Maputaland $\left(2,506 \mathrm{~km}^{2}\right)$ is a plain interspersed with woodlands and grasslands (Matthews et al., 2001). Tembe (c. $300 \mathrm{~km}^{2}$ ), in north-eastern South Africa, was proclaimed in 1983 and became completely fenced in 1989. Only staff live in the Park, and local people harvest reeds inside. Tembe houses nearly 180 elephants (Morley \& van Aarde, 2007). Maputo (c. $800 \mathrm{~km}^{2}$ ), in southern Mozambique, is unfenced except for a $30 \mathrm{~km}$ stretch along the northwestern boundary. People live inside the Reserve. The Futi River corridor extends outside and south of Maputo, and people live there also. During our study c. 200 elephants populated the Reserve and the corridor (Ntumi et al., 2005). Etosha (c. 23,000 $\mathrm{km}^{2}$ ) is an arid Park in north-central Namibia (Fig. 1). The Park is fenced and holds c. 2,000 elephants (Etosha Ecological Institute, unpubl. data). 


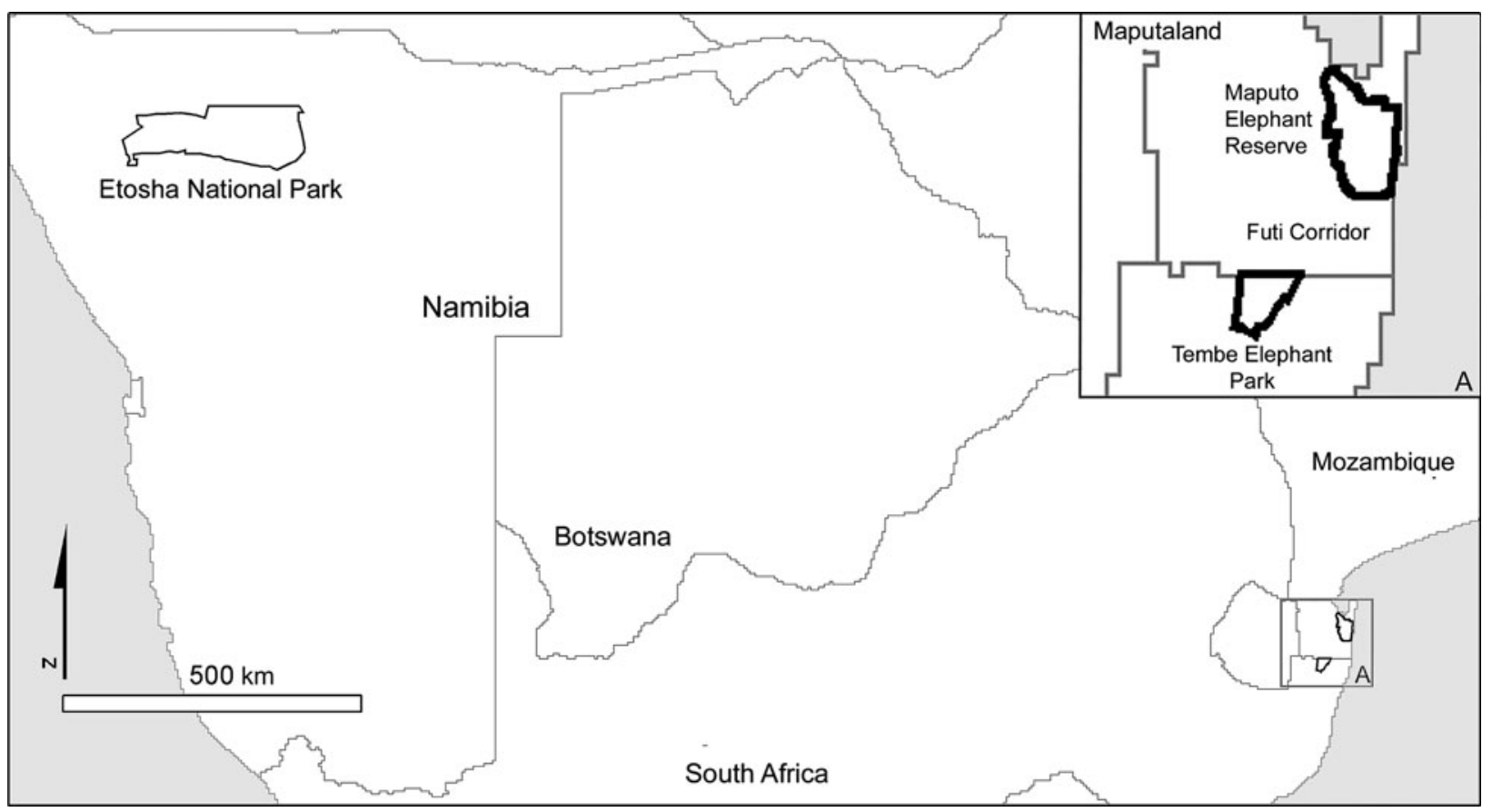

Fig. 1 The three sites for quantifying elephant habitat use, at opposing ends of the historical distribution of elephants in southern Africa: arid savannahs of Etosha National Park (Namibia), and the tropical woodlands of Tembe Elephant Park (South Africa) and of Maputaland, which includes Maputo Elephant Reserve and the intervening Futi River Corridor (Mozambique; inset A).

\section{Location data}

In Maputo and Tembe nine elephants wore collars recording their locations: three bulls and two cows in Maputo, and one bull and three cows in Tembe. Each cow was part of a separate herd. These location data cover four seasons: the wet seasons (November-March) of 2000 and 2001, and the dry seasons (April-October) of 2001 and 2002. Some collars malfunctioned, so we only covered one wet and dry season for the Tembe bull, and we missed a dry season for another bull in Maputo. The ARGOS satellite system tracked these elephants, with collars active for 24 hours, then off for 48 hours. Location data were often 2 and 5 hours apart, or separated by c. 2 days. As supplied, these data have three accuracy brackets: 300-500, 150-300 and 1-150 m. We only used points with accuracies better than $300 \mathrm{~m}$.

In Etosha we monitored six cows, each from a separate breeding herd of 14-28 elephants. Cows wore collars with GPS satellite units (model AWT SM2000E, Africa Wildlife Tracking). Comparing reported locations to known ones, these locations have a route mean square error of $<30 \mathrm{~m}$. GPS fixes were every 8 hours (de Beer et al., 2005). Our data covered the wet seasons of 2002 and 2003, and the dry season of 2003. Collars on two cows stopped logging data prematurely, so for them we missed two wet seasons.
All these datasets have time gaps because not every scheduled time results in a location fix. Reasons include thick vegetation, poor satellite positioning, improper collar angle, or topography blocking signals. Gaps are more common for Maputo and Tembe because some were created by removing the GPS fixes with accuracies $>300 \mathrm{~m}$. Therefore, location data can be separated by up to 55 hours in Maputo and Tembe, or 32 hours in Etosha. Both sites have a mean fix interval of 12 hours.

\section{Model variables}

Vegetation From Landsat 7 ETM+ imagery we created vegetation maps for each site using supervised classification techniques with maximum likelihood decision rules. One image covered Maputaland (August 1999) and another Tembe (April 2000). Etosha required two images (April 2000, 2002). In all sites we took multiple GPS points demarcating vegetation and vegetation transitions to develop signatures for mapping. The vegetation map for Tembe had nine categories: sand forest, closed woodland, open woodland, grass, sparse woodland, reeds/wetland, palm veldt, sand and water. Closed and open woodlands consisted of bushveldt species such as Terminalia sericea and Acacia burkei (Matthews et al., 2001). Their species composition is completely different from sand forests, and spectrally dissimilar. Sand forests 
show great diversity in species composition but we did not distinguish them. These nine vegetation types also occurred in Maputo except for sparse woodland, caused by frequent burning in sections of Tembe (Matthews et al., 2001). Maputo had two additional vegetation types: Eucalyptus plantations and mangrove forests. Etosha had 11 vegetation categories: water, Colophospermum mopane, Catophractes alexandri, Acacia nebrownii, steppe/grass, Acacia-dominated savannah, a mopane and Catophractes mixed community type, mixed tree savannahs, dolomites, Peschuel vegetation, and Lonchocarpus savannahs. Vegetation maps were smoothed with a majority filter, using a $3 * 3$ pixel kernel (Wilkie \& Finn, 1996). This reassigned each centre pixel the cell value corresponding to the majority value of pixels within the kernel (the pixel retains its original value when majority is unachieved). We employed a kappa statistic to validate each vegetation map, using GPS points independently acquired and separate from those employed in map creation (Wilkie \& Finn, 1996). The kappa statistic accounts for errors of omission and commission in each vegetation class. The values are 80,79 and $76 \%$, for Maputo, Tembe and Etosha, respectively.

Elephants did not use all vegetation types and it is inappropriate to include irrelevant biological variables (Burnham \& Anderson, 2002). Therefore, we determined the principal vegetation types that elephants used by generating a ratio comparing the percentage of locations for an elephant in a given vegetation class against the proportion of that same class in the landscape (for each elephant, between seasons; Manley et al., 1993). We only included variables with ratios $>1.5$ and encompassing at least $20 \%$ of elephant GPS locations populated models. These included closed woodlands for Tembe and Maputo, reeds for Maputo, and mopane, and Acacia-dominated savannah plus Acacia nebrownii for Etosha. The vegetation maps were converted from the $30 \mathrm{~m}$ scale of the Landsat imagery to a $500 \mathrm{~m}$ scale. The information within each larger pixel consisted of the proportion of the pixel occupied by each vegetation class.

Water In Tembe and Maputo we identified water directly from the satellite imagery and, by association, with reed beds. In Maputo we excluded brackish lakes and salt-water bodies, and smoothed the classification with a $5 * 5$ majority filter to eliminate small, mostly ephemeral water sources. We did not assess differences in water availability between seasons for Maputo because clouds masked wet season imagery. Tembe has water in the Futi River and artificial boreholes. For the dry season we only considered water present in the Futi River, plus two reliable boreholes (Vukazini and Mahlasela). For the wet season we added large natural pans that collect rainwater. Etosha contains boreholes, dams and a few natural springs. The dry season water map considers only permanent springs and reliable, freshwater boreholes. The water map for the wet season includes all springs, reliable and freshwater boreholes, plus artificial dams where water collects. In all locations small depressions fill with rainwater during wet seasons. These temporary water sources were too small and numerous to map. Therefore in wet seasons our estimates of water availability are conservative. Each water map is resolved to a $500 \mathrm{~m}$ grid. The value for each cell represents the Euclidean distance to the nearest water source.

Settlements Humans can influence elephant presence by chasing them from homes or crops, or by killing them (Hoare \& du Toit, 1999). We mapped homesteads in Maputo using GPS during aerial surveys in 2001 and 2002. Village locations came from regional maps. We calculated the Euclidean distance from each cell on a $500 \mathrm{~m}$ grid to the nearest settlement.

\section{Habitat preference models}

We modelled the tracking data by calculating the probability of each movement segment from one location fix to the next. Firstly, we calculated the relative attractiveness of each landscape cell from an elephant's current location. Then we employed a series of alternative models to determine the values representing this attractiveness. Lastly, we searched for the model most likely to have produced the observed data. All models contained the distance from current location as a declining exponential function. We do not present tests of its significance; preliminary analyses indicated that it was always important. Models also included anywhere from zero to two landscape variables, each presented in exponential or logistic-type sigmoidal forms. An exponential form signifies a gradual preference: it is always better to have more, or less, of that variable. A sigmoidal form indicates a threshold: an elephant may be content to be within, for example, a few $\mathrm{km}$ of water. We used exponential and logistic functions over linear or quadratic forms because all of our landscape variables are non-negative. Moreover, the attractiveness function is also non-negative as it is calculated as the product of the functions from each variable (also non-negative).

Let the landscape be represented as a set of $C$ grid cells, $c=1,2, \ldots, C$. An elephant's location on this landscape at time step $t(t=1,2, \ldots, T)$ is given by $l_{t}$. From there, the relative attractiveness of any cell $c$ is

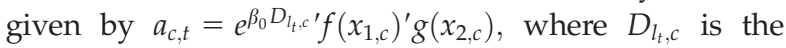
distance of $c$ from the current location $l_{t}, x_{n, c}$ is the value of the landscape variable $n$ in cell $c$, and $f$ and $g$ are either exponential $f(x), g(x)=e^{\beta_{1} x}$ or sigmoidal $f(x), g(x)=$ $\frac{e^{\beta_{1}+\beta_{2} x}}{1+e^{\beta_{1}+\beta_{2} x}}$ functions, with the beta terms as parameters. Therefore, the equation to determine the relative 
attractiveness of a cell may contain zero, one or two landscape terms, depending on the model, and up to five parameters in total.

The attractiveness of a cell is given by a product of terms, each of which scales it according to a particular variable. The scaling is relative. Thus, in an exponential model for distance from water a value of $\beta_{0}=-0.5$ would mean that a cell $1 \mathrm{~km}$ from water is $61 \%$ as good as one immediately next to water, a cell two units away $38 \%$ as good, and so on. The $a_{c, t}$ values represent the attractiveness of the landscape from the point of view of an elephant in its current location $\left(l_{t}\right)$. We calculate $p_{t}$, the probability that an elephant will move to location $l_{t+1}$ in the next time step, by dividing that cell's attractiveness by the total attractiveness of the landscape: $p_{t}=\frac{a_{l_{t+1}, t}}{\sum_{c} a_{c, t}}$. Obviously, if all cells were equally attractive (i.e. selection was random), and the landscape had 100 cells, the probability of an elephant moving to any one of them would be $1 / 100$ or 0.01 . For each time series of $T$ locations, we calculated $T-1$ probabilities, one for every movement step. We then calculated the likelihood of the model as the product of these: $L=\Pi_{t=1}^{T-1} p_{t}$.

\section{Model fitting}

The likelihood is maximized by non-linear search over the parameter space of the model, which may have anywhere from one dimension (distance only) to five dimensions (distance plus two variables having sigmoidal functions). The fitting process is computationally demanding as it requires the calculation of $T$ new probability landscapes for each iteration. Hence, the landscape was represented as $500 * 500 \mathrm{~m}$ cells, rather than the $30 * 30 \mathrm{~m}$ cells originally derived from satellite imagery. For Tembe and Etosha we assessed two variables (proportion of vegetation and distance from water), making nine possible models. For Maputo, we added distance from human settlements but only assessed models containing up to two out of the three variables (because the fitting process is slow, and often does not converge, for three variables), making 19 possible models.

Starting parameters were based on intuition and, for more complex models, on the fits of simpler models. We also eliminated the most complex models, with sigmoidal forms of two variables, if the sigmoidal form of either variable produced a negligible improvement over its exponential form in a simpler model (tests supported use of the simpler models).

Information-theory statistics summarize the trade-off between model fit and complexity in a number composed of two parts: lack of fit and a penalty term. Lack of fit is measured by $2 \ln (L)$ where $L$ is the maximized likelihood of the model. We used the penalty term from Akaike's Information Criterion (AIC). The larger the
AIC distance between any two models, the less relatively plausible is the model with the higher value (smaller AIC values are more parsimonious). Models were sorted by AIC value and assigned weights $\left(W_{i}\right)$ representing the probability that the $i$ th model is the best model in the candidate group.

$$
W_{i}=\frac{e^{-1 / 2}\left(\mathrm{AIC}_{i}-\mathrm{AIC}_{\min }\right)}{\sum_{i} e^{-1 / 2}\left(\mathrm{AIC}_{i}-\mathrm{AIC}_{\min }\right)}
$$

Models having $W_{i}$ within $90 \%$ of the best model define our confidence set (Appendix). This lies within suggested bounds for ranking AIC models (Burnham \& Anderson, 2002).

\section{Visualizing habitat selection and use}

We visualized 'intrinsic' habitat value by mapping the fitted models without the distance component across each landscape. (The distance component has nothing to do with intrinsic value, only value relative to a specified location.) We made maps representing each individual season. If there was one model in one season, it produced its own value map. In cases with more than one plausible model we combined the resulting maps into a weighted average map, using weights given by the AIC weights for the respective models. In each location we also averaged the individual season maps for all elephants, separated by sex and season. These indicated common areas of high habitat value in each site.

From each intrinsic value map we created a 'contextual value' map that incorporates neighbourhood quality, modified by movement costs. To do this, an exponential decay function (describing the effect of distance on habitat value) was applied over the intrinsic value maps as a smoothing kernel. The exponential parameter will vary by elephant mobility, and time scale (shorter times increase the apparent importance of local surroundings). We chose a common value of -1 , which falls within the range of fitted values in this study and represents a typical elephant with a GPS fix interval of $c .8$ hours.

\section{Results}

Detailed model fitting data are in the Appendix. Here, we summarize variables appearing in the better supported models (those with AIC weights >0.4). All elephants preferred areas nearby to those farther away (other things being equal; Fig. 2a,d,i). Half distance, the distance that attractiveness drops to $50 \%$ from the current location, illustrates this preference. These are similar between locations, irrespective of differences between GPS fix intervals. Half distances are c. 1, 1.5 and $2 \mathrm{~km}$ for Tembe, Maputo and Etosha, respectively. 

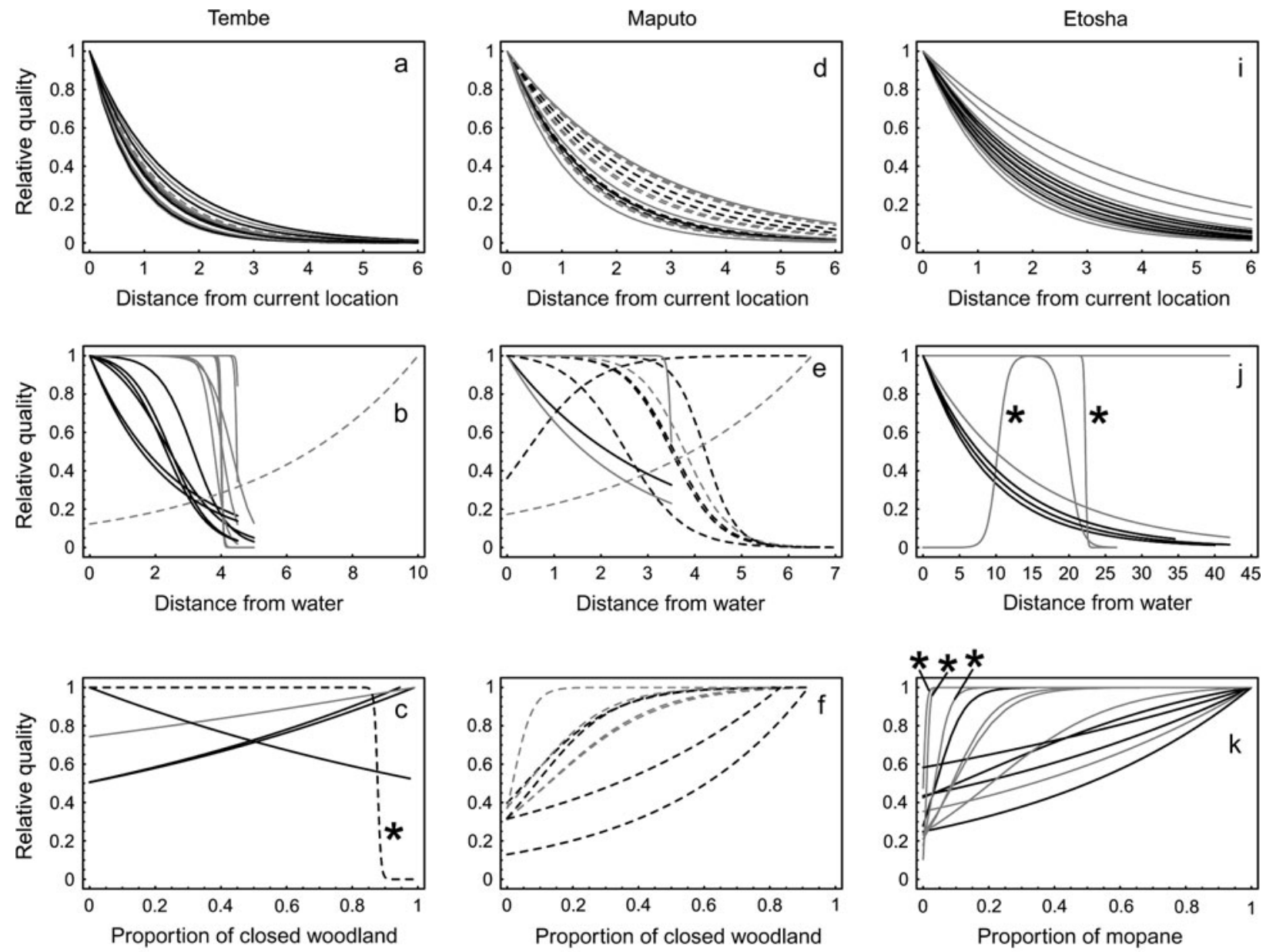

Fig. 2 Visualizations for the shapes of the functions describing variation in the relative attractiveness of various landscape variables (including distance from an elephant's current location, water, human settlements and the proportion of closed woodland, mopane, reeds, and acacia, in the three study areas. Plots represent models with AIC weights $>0.4$ (except A. newbrownii). Some lines overlap and asterisks indicate plots whose models contain parameter values of \pm 200 . Curves for these were approximated since models did not converge (i.e. the fitting algorithm ended because the process sought an arbitrarily large value of the parameter with little improvement in fit, as measured by the likelihood). Grey and black curves represent elephants in wet and dry seasons respectively, with solid lines for cows and dashed lines representing bulls. All curves are scaled so that the most attractive pixel has a value of one (curves begin and end at
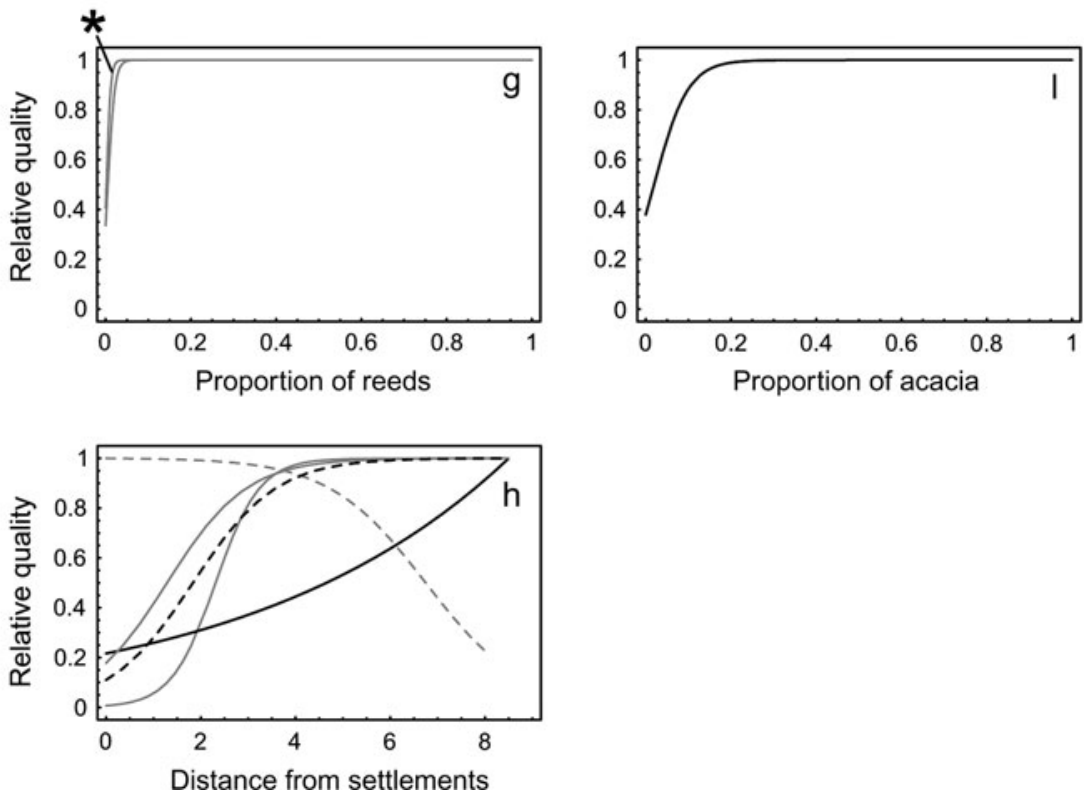
the minimum and maximum observed values of the variable in question). Lettering on plots is for referencing in the text. 


\section{Distance from water}

Generally, elephants chose places near water. In Tembe most of the best models only contained distance from water, with sigmoidal curves. These indicated that elephants stayed closer to water in the dry season (half distances 2-3 km) than the wet season (half distances 4$5 \mathrm{~km}$; Fig. 2b). Similarly, selection for water in Etosha was strong. Water entered all but four models, often exponentially. Here the half distances are larger: 7-9 km and 10-23 km during the dry and wet seasons, respectively. Just one elephant avoided water, in one of the wet seasons. In Etosha models with water always included a vegetation variable. In Maputo water entered half the models for cows, and always occurred alongside distance from settlements. There was little seasonal variation, with all half distances $2-4 \mathrm{~km}$. Two models without water contained reed vegetation, which certainly acted as a surrogate for water (Appendix, Fig. 2g). Bulls in Maputo had water in half the models, always with a closed woodland variable. A bull from Maputo (during a wet and dry season) and Tembe (wet season) appeared to avoid water.

\section{Vegetation}

High proportions of closed woodland rarely entered top models for cows in Tembe (only two), and one elephant avoided it (Elephant 17, dry season 2002). Cows in Maputo selected areas with high proportions of reeds in two seasons, while avoiding settlements (see below). Note that whereas reeds indicated water, water did not always indicate reeds. Therefore, models with high proportions of reeds occurring alone are powerful predictors (being surrogates for water). When reeds and distance from water appeared together, the importance of reeds was reduced, and the nature of the relationship complicated. In Etosha four out of six elephants favoured high proportions of mopane during all seasons, and another favoured high proportions of mopane in two out of three seasons (preferring areas with high cover of $A$. nebrownii in a single dry season, perhaps an anomaly). The final elephant sought locations with high proportions of Acacia. While mopane vegetation was favoured by most elephants in this study, locations with high concentrations of these species vary throughout the Park (Fig. 3). This study did not evaluate if elephants moved long distances between areas based on vegetation differences. Rather, elephant preferences appeared to be based on the vegetation types that were locally dominant in the elephants' vicinity. Clearly, elephants in Etosha sought places with high concentrations of vegetation (as long as they were sufficiently close to water), for it entered every top model but two (from wet seasons) with the relationship tending to be sigmoidal. Proportion of vegetation need not exceed c. $50 \%$ in dry seasons (c. $30 \%$ for wet seasons) before habitat attractiveness rose above half (Fig. 2k,1). The Tembe bull did not select areas with high concentrations of vegetation. Places with high proportions of closed woodland, however, were good predictors for Maputo bulls. It increased habitat use in all but two models (Fig. 2f). In summary, cows in Tembe and Maputo did not actively seek areas with high proportions of vegetation. Bulls in Maputo and cows in Etosha did.

\section{People}

Only in Maputo did elephants encounter people on a regular basis. This variable entered three cow and two bull models, respectively. When present, elephants preferred areas $>4 \mathrm{~km}$ from settlements. One bull appeared attracted to settlements (elephant 13 in wet season 2001). Distances from human settlements appeared the best predictor for cows (Fig. 2h).

\section{Habitat preference maps}

We averaged habitat preference maps by weighting the models for all elephants in a site. Best areas are yellow. Green shading indicates preferences increasing over five categories of equal area (Fig. 3). These examples focus on cows during dry seasons because cows have the greatest impact on population demography, and dry seasons are physiologically challenging. The intrinsic preference maps illustrated fine scale variation in habitat attractiveness. In Tembe areas near water, especially the Futi River, were key habitat for cows in dry seasons. In Maputo the best habitat occurred near water, far from people, in the midst of a reed-bed. During the dry seasons in Etosha areas of greatest preference were close to natural and artificial water holes surrounded by high proportions of mopane vegetation. The smoothed, contextual maps are arguably most useful from a management perspective. These eliminated stray pixels of high-use habitat surrounded by less attractive regions, and consolidated areas of high use, making them easier to delineate. The smoothing is founded on elephant movements, to improve representation of habitat preferences. Locations in yellow indicated the most important concentrations of quality habitat for elephants.

\section{Discussion}

Elephants inhabit a diversity of environments and this project focused on two environmental extremes: semiarid deserts and evergreen savannahs. Our models included biologically important parameters known to 
Tembe Elephant Park
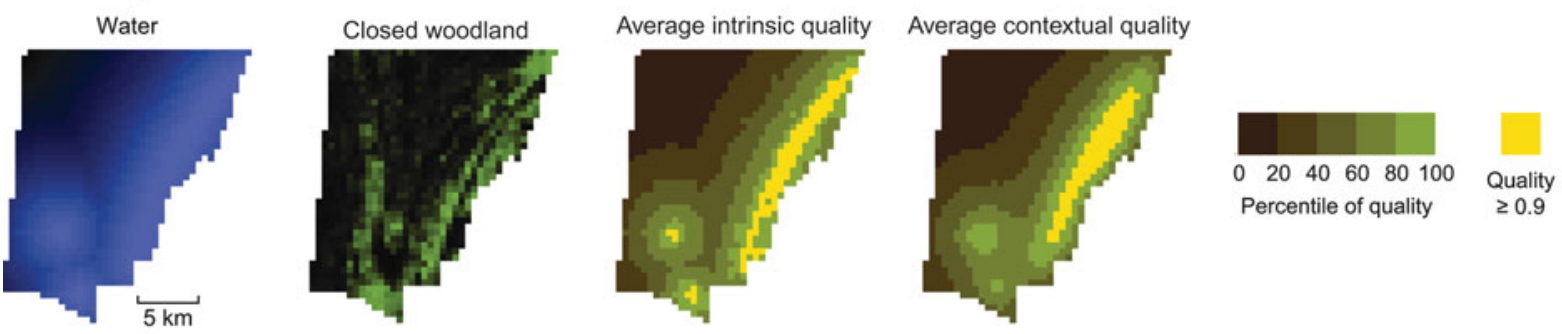

Maputo Elephant Reserve and Futi River Corridor
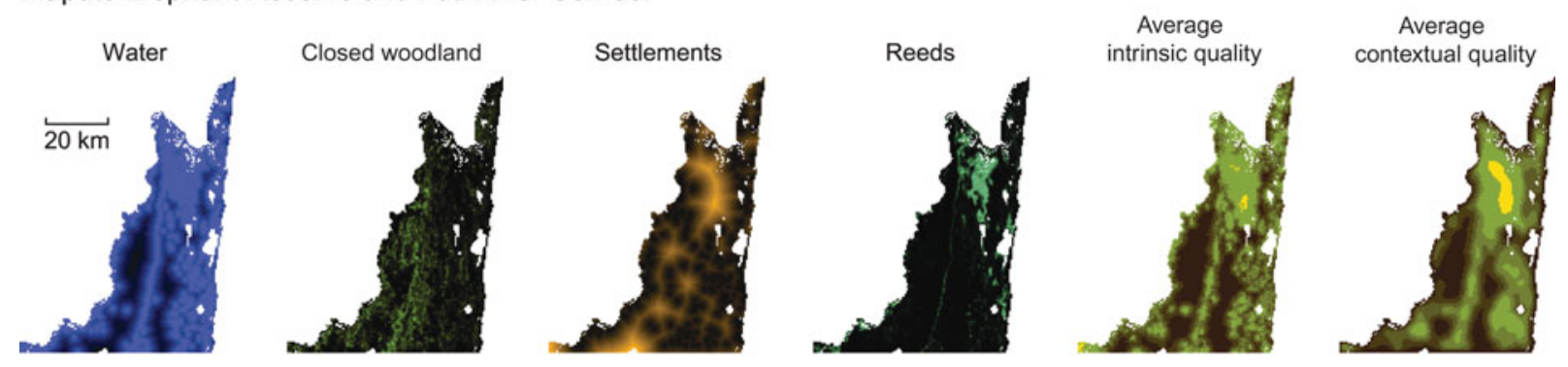

Etosha National Park
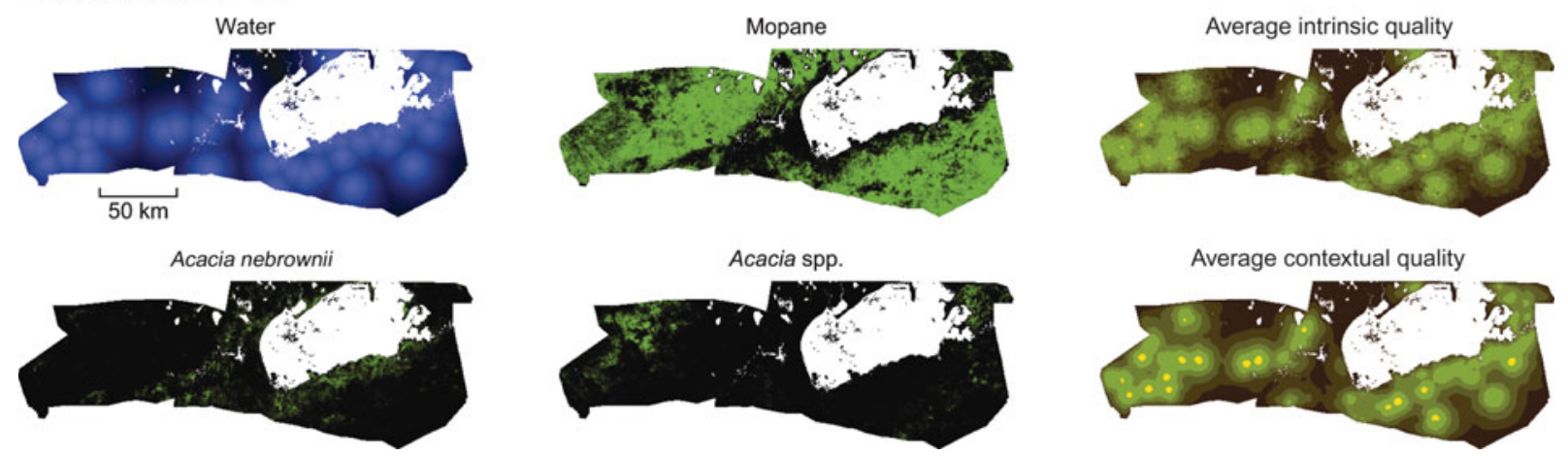

Fig. 3 Important landscape variables and the model-derived intrinsic and contextual quality maps. Pixels are $500 \mathrm{~m}$ on a side for each map. For vegetation variables, as the colour becomes lighter green the relative proportion of that vegetation type rises. Water distance is scaled so the maximum possible distance is portrayed as black, and zero distance as solid blue, whereas settlement distance is scaled so that the zero distance is portrayed as black, and the maximum possible distance as solid orange. Quality maps represent the preferences of cows only during dry seasons, and are based on averages across models and individuals as described in the text. Each quality map is divided into five regions, shown by varying levels of green, such that each region contains one-fifth of the total area of the Park (percentiles of quality). Regions containing all pixels whose quality is within $10 \%$ of the quality of the best pixel are coloured yellow. This area is not fixed in size but rather a subset of the best percentile region. Intrinsic maps show per-pixel quality. Contextual maps are smoothed with an exponential weighted average kernel, based on the distances that elephants move. In Tembe the best areas are associated with water. In Maputo cows avoided human settlements. In Etosha quality is associated with water and high concentration of various woodland types, especially mopane.

affect elephants and ones we can measure over wideranging landscapes: proportions of vegetation, water accessibility, and proximity to human settlements. Across all sites, elephants displayed similarities in their use of the landscape. These similarities suggest the following 'rules':

Distance travelled Within seasons, elephants travel less than a few $\mathrm{km}$ from day to day when essential resources occur locally. Other factors modify this rule substantially, however.
Water Presence of water is often the best predictor for elephants, especially for females, and particularly during dry seasons and in dry areas. This limits elephants to permanent water sources, including artificial water holes, in the dry season. During the wet season temporary pools allow movement across more of the landscape. Elephants in Etosha also travelled furthest from water in the dry season, which seems counter-intuitive, considering it is the driest site overall. The explanation lies in the distribution of vegetation. 
Vegetation If it is close enough to water an elephant seeks areas with high vegetation cover. In tropical woodlands, vegetation is abundant, productive and diverse, and often occurs close to water. As with our earlier illustration using beer, elephants need not select or move far from water to obtain vegetation. It rarely increased habitat use for cows. A strong preference for vegetation is indicated from Etosha. Vegetation there is sparser, relatively low in productivity, and species-poor in terms of an elephant's forage. Distances between vegetation and water are greater, and so elephants travelled farther from water to feed.

Human presence If settlements are present, cows tend to stay $5 \mathrm{~km}$ or more away from them. In Maputo distance from settlements was the best predictor of habitat preference for cows. It had little influence on bulls, leading to the possibility that Maputo bulls may encounter people more often. Unfortunately, elephants and people do not always mix well (Hoare \& Du Toit, 1999). Many southern African countries cannot afford the fences to prevent that mixing.

Other things being equal, elephants move short distances from day to day, keep close to water, select the highest vegetation cover, and avoid people. None of these factors is surprising. The relative importance of each of these factors, however, was not obvious a priori. Nor was it obvious to us how food preferences might change when comparing dry and wet sites. The confounding effects of each variable on the other, especially in light of the complex and often counter-intuitive features of preference, prevent simple diagnosis.

Proximity to water is not merely the most important variable but the one managers can more easily control. The consequence for dry sites, where water is relatively sparse, is extreme browsing pressure on vegetation near these water holes, from elephants and other ungulates. In Etosha, for example, vegetation shows severe signs of degradation up to $4 \mathrm{~km}$ away (de Beer et al., 2006). Elephants' natural tendency to move relatively short distances exacerbates this problem. Alternatively, vegetation cover can moderate the effect, for example, when water holes occur in preferred habitats (i.e. high proportions of vegetation) and productive environments (vegetation more apt to recover).

The need to improve future management of elephants and their interactions with humans and ecosystems is clear. Rising numbers of elephants in protected areas, ecosystem degradation, and human-elephant conflict are issues of concern to elephant managers, conservation biologists, local communities and political leaders (Assessment of South African Elephant Management, 2008). We advise that a promising approach for minimizing these issues is by providing elephants more space. This strategy would re-establish linkages between elephant populations, and therefore facilitate elephant movements, ease pressures on habitats, enable more natural population regulation, and reduce conflicts when planned in concert with local communities (van Aarde et al., 2006; van Aarde \& Jackson, 2007; Chamaillé-Jammes et al., 2008). Recent literature on elephant social dynamics and the spatial use patterns of elephant groups also suggests making more area available to elephants to ensure social structuring and outbreeding (Archie et al., 2007; Wittemyer et al., 2007). When providing more space, an obvious consideration is to ensure that potential areas are biologically meaningful to elephants. Meeting this objective requires extrapolating the rules describing elephant habitat preferences across the broader landscape of southern Africa.

In caricature, elephants prefer to move little, eat well, drink easily, and avoid people. If more space is made available for them, they will probably disperse to areas near water, with high vegetation cover, and relatively distant from humans. Managers can oblige them by making water accessible and, if so, then they should anticipate high impacts on the vegetation nearby. As may be expected for such generalized feeders, that vegetation involves a wide variety of habitats.

\section{Acknowledgements}

The University of Pretoria, the Namibian Ministry of Environment and Tourism, the Etosha Ecological Institute, Ezemwelo KZN Wildife and Direcção Nacional de Florestas e Fauna Bravia sanctioned our studies. Financial support came through grants to R.J. van Aarde from the National Research Foundation, the US Fish \& Wildlife Service, the Peace Parks Foundation, WildlifeWins, and the Walt Disney Grant Foundation. We thank Y. de Beer, D.G. Erasmus, N. Fairall, J. Fourie, R. Guldemond, P. Halpin, G. Hartshorn, G. Katul, W. Killian, R. Morley, C. Tucker, W. Versfeld and T. Wassenaar for their ideas, help and generosity.

\section{References}

Archie, E.A., Moss, C.J. \& Alberts, S.C. (2006) The ties that bind: genetic relatedness predicts the fission and fusion of social groups in wild African elephants. Proceedings of the Royal Society B, 273, 513-522.

Assessment of South African Elephant Management (2008) Http:/ / www.elephantassessment.co.za/ [accessed 4 January 2008].

Chamaillé-Jammes, S., Fritz, H., Valeix, M., Murindagomo, F. \& Clobert, J. (2008) Resource variability, aggregation and direct density dependence in an open context: the local regulation of an African elephant population. Journal of Animal Ecology, 77, 135-144.

Burnham, K.P. \& Anderson, D.R. (2002) Model Selection and Multi-model Inference: A Practical Information-theoretic Approach. Springer-Verlag, New York, USA. 
de Beer, Y., Kilian, W., Versfeld, W. \& van Aarde, R.J. (2006) Elephants and low rainfall alter woody vegetation in Etosha National Park, Namibia. Journal of Arid Environments, 64, 412-421.

Douglas-Hamilton, I. (1987) African elephants: population trends and their causes. Oryx 12, 11-24.

Guldemond, R.A.R. \& van Aarde, R.J. (2007) The impact of elephants on plants and their community variables in South Africa's Maputaland. African Journal of Ecology, 45, 327-335.

Hoare, R.E. \& Du Toit, J.T. (1999) Coexistence between people and elephants in African savannas. Conservation Biology, 13, 633-639.

IUCN (2007) 2007 IUCN Red List of Threatened Species. IUCN, Gland, Switzerland. Http:/ / www.iucnredlist.org [accessed 14 November 2007].

Manley, B.F.J., Macdonald, L.L. \& Thomas, D.L. (1993) Resource Selection by Animals: Statistical Design and Analysis for Field Studies. Chapman \& Hall, London, UK.

Matthews, W.S., van Wyk, A.E., van Rooyan, N. \& Botha, G.A. (2001) Vegetation of the Tembe Elephant Park, Maputaland, South Africa. South African Journal of Botany, $67,573-594$.

Millspaugh, J.J. \& Marzluff, J.M. (2001) Radio Tracking and Animal Populations. Academic Press, San Diego, California.

Morley, R.C. \& van Aarde, R.J. (2007) Estimating abundance for a savanna elephant population using mark-resight methods: a case study for the Tembe Elephant Park, South Africa. Journal of Zoology, 271, 418-427.

Ntumi, C.P., van Aarde, R.J., Fairall, N. \& De Boer, W.F. (2005) Use of space and habitat by elephants (Loxodonta africana) in the Maputo Elephant Reserve, Mozambique. South African Journal of Wildlife Research, 35, 139-146.

Owen-Smith, N. (1996) Ecological guidelines for water points in extensive protected areas. South African Journal of Wildlife Resources, 26, 107-112.

Pimm, S.L. \& van Aarde, R.J. (2001) Population control: African elephants and contraception. Nature, 411, 766.

van Aarde, R.J. \& Jackson, T.P. (2007) Megaparks for metapopulations: addressing the causes of locally high elephant numbers in southern Africa. Biological Conservation, 134, 289-297.

van Aarde, R.J., Jackson, T.P. \& Ferreira, S.M. (2006)

Conservation science and elephant management in southern Africa. South African Journal of Science, 102, 385-388. van Aarde, R.J., Whyte, I. \& Pimm, S.L. (1999) Culling and the dynamics of the Kruger National Park African elephant population. Animal Conservation, 2, 287-294.

White, G. \& Garrott, R. (1990) Analysis of Wildlife Radio-tracking Data. Academic Press, New York, USA.

Whyte, I.J., van Aarde, R.J. \& Pimm, S.L. (2003) Kruger's elephant population: its size and consequences for ecosystem heterogeneity. In The Kruger Experience: Ecology and Management of Savanna Heterogeneity (eds J.T. du Toit, H. Biggs \& K. Rodgers), pp. 332-248. Island Press, Washington, DC, USA.

Wilkie, D.S. \& Finn, J.T. (1996) Remote Sensing Imagery for Natural Resource Monitoring. Columbia University Press, New York, USA.

Wittemyer, G., Getz, W.M., Vollrath, F. \& Douglas-Hamilton, I. (2007) Social dominance, seasonal movements, and spatial segregation in African elephants: a contribution to conservation behavior. Behavioral Ecology and Sociobiology, 61, 1919-1931.

\section{Appendix}

The appendix for this article is available online at http:/ /journals.cambridge.org

\section{Biographical sketches}

Grant Harris models species and habitat relationships to improve the management and conservation of birds and mammals. He investigates patterns in biodiversity and the relationships between species ranges and extinction threat. Gareth Russell specializes in population and community dynamics, particularly of rare and endangered species. He is interested in how differences between passive and active movements affect population and metapopulation dynamics. Rudi J. van Aarde is Director of the Conservation Ecology Research Unit, University of Pretoria, South Africa. He examines the restoration of populations and communities as a contribution to conservation, with a focus on elephants throughout southern Africa. Stuart Pimm examines species extinction at all scales, trying to find practical solutions to prevent them. That work leads him to the Everglades of Florida and the forests of Brazil and Southern Africa. 